\title{
O Trabalho Imaterial do Designer e a Sustentabilidade Impasses
}

http://dx.doi.org/10.21527/2237-6453.2020.51.297-316

Recebido em: $17 / 5 / 2019$

Aceito em: 4/12/2019

Sonia Regina Vargas Mansano, ${ }^{1}$ Ana Maria da Rocha Périgo ${ }^{2}$

\begin{abstract}
RESUMO
A história do design acompanhou a história do desenvolvimento das indústrias, cabendo aos profissionais dessa área projetar objetos, desenvolver peças gráficas e organizar processos que favorecessem a produção e o consumo de mercadorias. Atento a esse contexto, o presente estudo teve por objetivo geral compreender a importância do trabalho imaterial do designer, bem como as possibilidades de sua vinculação com a sustentabilidade. Para isso, foi realizada uma pesquisa qualitativa, da qual participaram quatro designers vinculados a dois estúdios localizados em uma cidade do norte do Estado do Paraná, que relataram suas experiências profissionais e seus vínculos com o meio ambiente. Os resultados demonstraram que a profissão do designer encontra várias maneiras de se conectar com a preservação da natureza, mas diversas são as dificuldades para expandir esse vínculo. Ao final da pesquisa constatou-se que o trabalho do designer ocorre em meio a uma série de impasses que envolvem as demandas de produção das empresas, mas não se reduz a elas, podendo também trazer para o cotidiano de suas atividades uma preocupação efetiva com a natureza, com o meio ambiente e com os seres humanos.
\end{abstract}

Palavras-chave: Designer. Trabalho imaterial. Consumo. Sustentabilidade. Resistência.

\section{THE IMMATERIAL LABOR OF THE DESIGNER AND SUSTAINABILITY: DEAD ENDS}

\section{ABSTRACT}

The history of design followed the history of the development of the industries, and to the professionals of this area designing objects, develop graphic pieces and organizing processes that favors the production and consumption of goods. Aware of that context, the present study aimed to understand the importance of immaterial work of the designer, as well as the possibilities of your binding to sustainability. For this, a qualitative research, in which participated four designers linked the two studios located in a northern city of Paraná State, which reported their experience and their linkages with the environment. The results showed that the profession of designer finds different ways to connect with the preservation of nature, but various difficulties to expand that bond. At the end of the survey, noted that the work of the designer occurs amid a series of standoffs involving the demands of production. But cannot be reduced to them and may also bring to the daily life of its activities effective concern with nature, the environment and human beings.

Keywords: Designer. Immaterial labor. Consumption. Sustainability. Resistance.

\footnotetext{
${ }^{1}$ Doutora em Psicologia Clínica pela Pontifícia Universidade Católica de São Paulo (PUC/SP). Professora da Universidade Estadual de Londrina (UEL).smansano@sercomtel.com.br

${ }^{2}$ Graduada em Desenho Industrial pela Universidade do Norte do Paraná (Unopar). Mestre em Administração pela Universidade Estadual de Londrina (UEL). aninhaperigo@gmail.com
} 
É notável o quanto a natureza vem sendo explorada de maneira predatória desde a primeira Revolução Industrial com a finalidade de produzir mercadorias e objetos de consumo para a massa populacional. Esses objetos, à medida que foram elaborados e fabricados, passaram a fazer parte do cotidiano das sociedades, suprindo algumas necessidades de uso e outras relacionadas à satisfação de ordem subjetiva. Tamanho foi o crescimento dessa produção e consumo que uma forte engrenagem econômica de exploração foi estabelecida, tornando-se primordial aos sistemas produtivos dominantes.

No final da década de 60 , a preocupação com a degradação da natureza e os efeitos gerados por esse cenário de exploração predatória geraram discussões políticas e socioeconômicas a respeito dos efeitos nefastos de tal prática (O'CONNOR, 2002; CASTRO, 2004). O que se constata é que os recursos naturais, imprescindíveis para a produção industrial, vêm evidenciando uma escassez e, consequentemente, uma grave degradação de ecossistemas complexos, o que compromete não apenas a dimensão ambiental, mas também as sociais, culturais e políticas do planeta (SACHS, 2007).

Diante desse panorama de exploração sistemática da natureza, a presente pesquisa teve por objetivo geral compreender as atividades de um profissional que participa diretamente da produção industrial: o designer. Trata-se de um especialista responsável por solucionar problemas e organizar a produção industrial, projetando e criando produtos atrativos ao público consumidor e que, ao mesmo tempo, sejam compatíveis com o funcionamento das máquinas, aumentando o ritmo e a quantidade da produção (CARDOSO, 2008; WOLLNER, 2002).

$\mathrm{O}$ estudo foi dividido em dois momentos. Primeiramente, foi realizada uma análise teórica e crítica que aborda a consolidação da economia capitalista no século 20 , bem como a estreita relação entre os processos industriais, o consumo e a obsolescência das mercadorias. Busca-se compreender, na sequência, um profissional específico que participa desse processo, o designer, cuja atividade é descrita como um trabalho de tipo imaterial. Por fim, abordou-se a dimensão social e política do design na sociedade contemporânea e suas implicações com as questões referentes à sustentabilidade. $\mathrm{Na}$ parte empírica, a pesquisa qualitativa contou com a participação de quatro designers vinculados a dois estúdios de uma cidade de médio porte localizada no norte do Estado do Paraná. Estes participantes relataram suas experiências profissionais e seus vínculos com o meio ambiente.

Estabelecendo uma interface entre teoria e prática, o presente estudo justificou-se por apresentar uma leitura crítica das atividades do designer, abordando a conjugação entre produção e consumo, os agentes sociais que participam da sua consolidação, bem como as possibilidades de comprometimento desse profissional com a preservação do meio ambiente. Como resultado parcial, foi possível constatar que o modo de vida voltado para o consumo está longe de problematizar os danos, as questões e os impasses que essa prática engendra no cotidiano contemporâneo, em especial no que se refere à dimensão socioambiental. 


\section{O TRABALHO IMATERIAL DO DESIGNER E SUA VINCULAÇÃO COM O MEIO AMBIENTE}

A história social do designer, como profissão, acompanha o avanço da organização capitalista no século 20 que, em parte, pode ser explicada pela ascensão econômica dos Estados Unidos, ocorrida durante a Primeira Guerra Mundial e consolidada ao final da Segunda. Isso ocorreu em razão de alguns fatores decisivos, a exemplo do desenvolvimento da indústria armamentista, o que possibilitou que este país investisse e melhorasse seus processos industriais, alavancando uma forte política econômica e tecnológica (HOBSBAWM, 1995). Deveu-se também à sua localização geográfica, tendo em vista que este país encontrava-se distante dos locais do conflito, o que evitou a perda da vida de civis e o investimento na reconstrução das cidades afetadas pelas Guerras (SODRÉ, 1963). Outro fator foi o esgotamento econômico da Alemanha, Inglaterra, França e Holanda ocorrido entre as Guerras que, segundo Hobsbawm (1995, p. 59), "deixaram os beligerantes exaustos e enfraquecidos, a não ser os EUA, que saíram das duas guerras incólumes e enriquecidos, como os senhores econômicos do mundo".

Sodré (1963) considera que o fortalecimento econômico dos Estados Unidos tornou este país, desde o final da Primeira Guerra Mundial, um dos mais poderosos do mundo, cuja supremacia e forma de se relacionar com os países dependentes de seu capital fortaleceram sua condição imperialista e exploradora. Esclarece o autor:

O esforço econômico para derrotar a Alemanha e seus aliados levara o imperialismo a uma nova fase, quando os Estados Unidos assumiam uma posição de superioridade absoluta sobre todos os outros países que haviam atingido aquela etapa do desenvolvimento capitalista. Em todas as áreas mundiais a que o imperialismo aplicava o seu sistema, de que retirava proveitos, acelera-se a substituição de capitais ingleses, franceses, holandeses, alemães, por capitais norte-americanos. O Brasil será uma dessas áreas (SODRÉ, 1963, p. 316).

O crescimento industrial norte-americano valeu-se de estratégias amparadas em sistemas exploratórios colonizadores para se expandir. Foram instaladas grandes indústrias em países dependentes de seu capital, nos quais os governos punham à disposição dos colonizadores a mão de obra, a matéria-prima e os baixos impostos, tratando os estrangeiros como investidores internos. Isto, entretanto, não garantiu a troca de conhecimentos e tecnologias, privando os países dependentes do acesso aos avanços conquistados.

A dificuldade de acesso ao conhecimento tecnológico conduziu o Brasil, assim como outros países menos desenvolvidos economicamente, à condição de países exclusivamente agrários e exploratórios. Nota-se que o interesse das nações industrialmente desenvolvidas voltava-se ao acesso às matérias-primas que, após sua industrialização, se transformam em bens consumíveis, com preços mais elevados e ideais à comercialização. Sodré aborda essa estratégia introduzida no Brasil, ao mencionar:

Outras indústrias estrangeiras aqui instaladas atendem tão somente à necessidade de avizinhar-se da matéria-prima que utilizam. Em vez de pagar os fretes dessa matéria-prima que recebem daqui, e dos produtos acabados a que atendem, eliminando fretes de ida e volta, que encarecem a produção (SODRÉ, 1963, p. 317). 
Outro fator que contribuiu para que o consumo aumentasse foi a disseminação norte-americana do seu "estilo de vida", que poderia ser considerado, tanto pelos norte-americanos quanto pelos países menos desenvolvidos, como algo invejável. Para que essa ideia de satisfação e superioridade relacionada à sociedade de consumo norte-americana fosse desenvolvida e almejada, a estratégia concentrava-se na "venda" desse estilo, conectando-o à ideia de satisfação, felicidade, status e superioridade. A publicidade realizada junto aos meios de comunicação da época, como revistas, o rádio e o cinema, foi fundamental na disseminação massificada de tais valores.

A disseminação das práticas de consumo como algo satisfatório, encantador e vital, pode ser considerada uma face dessa colonização subjetiva (ROLNIK, 2003). Esta prática, que também atingiu o Brasil, é analisada por Tota (2009), que a considera uma ação abrangente, que coloniza as dimensões mais subjetivas como as maneiras de pensar e de agir. Holanda (1978) também aborda o longo alcance da estratégia dominadora como uma colonização em nossa História. Os brasileiros demonstraram alguma resistência à intervenção colonialista norte-americana, mas a aceitação desse estilo de vida acabou sendo maior. A conexão que os latifundiários e a burguesia brasileira mantiveram com o imperialismo norte-americano foi crucial na absorção dessa cultura importada, que visava ao consumo e ao crescimento econômico em sua vertente norte-americana (SODRÉ, 1963). Apesar de o imperialismo norte-americano ter-se iniciado por volta dos anos 20, a "americanização" do Brasil ficou mais evidente após a Segunda Guerra Mundial (HOLANDA, 1978).

Nota-se, portanto, que os mecanismos e estratégias de exploração comercial e cultural, caracterizados pelo colonialismo e imperialismo praticados pelos Estados Unidos e por países desenvolvidos economicamente, marcaram e estruturaram um sistema fortemente voltado para o aperfeiçoamento da produção industrial. Isso exacerbou práticas de consumo, cada vez mais marcadas pela obsolescência programada. Baudrillard (2008b), ao analisar a sociedade do pós-guerra, identificou os aspectos objetivos, técnicos, utilitários e subjetivos do consumo presentes nesse momento histórico, que colocava como necessária a relação direta entre os objetos, os fabricantes e os indivíduos consumidores. Ele assinala que houve uma transformação na relação entre o consumidor e o objeto, uma vez que:

Já não se refere a tal objeto na sua utilidade específica, mas ao conjunto de objetos na sua significação total. A máquina de lavar roupa, o frigorífico, a máquina de lavar louça, etc., possuem um sentido global e diferente do que têm individualmente como utensílios. A montra (vitrine), o anúncio publicitário, a firma produtora e a marca, que desempenha aqui papel essencial, impõem a visão coerente, coletiva, de uma espécie de totalidade quase indissociável, de cadeia que deixa aparecer como série organizada de objetos simples e se manifesta como encadeamento de significantes, na medida em que se significam um ao outro como super-objeto mais complexo e arrastando o consumidor para uma série de motivações mais complexas (BAUDRILLARD, 2008a, p. 15-16).

Para Baudrillard (2008a), o que comanda essa relação com o objeto é a maneira de organizar a produção, agora auxiliada pela publicidade. O que demanda o interesse pelo objeto é a sua transformação em signo compartilhado socialmente como algo investido de valor e afeto. O pós-guerra, portanto, foi o período no qual se fomentou o 
consumo, desviando o foco das demandas orientadas pela necessidade e pela subsistência, para a condição de identificação pessoal. Isso ajudou a incrementar o consumo e, por extensão, o descarte daquilo que não era mais interessante aos olhos do mercado, dando margem para a consolidação de uma nova prática: a obsolescência programada. Esta pode ser definida como um conjunto de ações que culminam em dois aspectos: o descarte do que ainda pode ser considerado utilizável, aderindo aos modismos de uma época, e pelo descarte do que já foi ofertado pela indústria com um breve prazo de validade. Esta mercadoria é constituída deliberadamente por materiais e sistemas frágeis e rapidamente inutilizáveis - seja pela sua condição física frágil ou pelo conjunto de signos obsoletos que a mesma contempla. Ferrara (1999) retrata o confronto entre valor de troca e o valor de uso como requisito fundamental para a produção de objetos com características que servem à lógica da obsolescência predominante, afirmando:

O binômio valor de troca/valor de uso, salientado pela industrialização, cria para a sociedade capitalista, a tensão entre o proprietário dos meios de produção e o consumidor. Ambos encontram-se, no mercado, como testemunhas de interesses opostos; por sua vez, o produto, enquanto mercadoria, se divide em duas categorias divergentes: valor de troca e valor de uso. Enquanto a lógica do produtor procura a massificação do valor de troca, a lógica do consumidor procura a valorização do uso (FERRARA, 1999, p. 193-194).

Na obsolescência programada, a projeção e a fabricação de produtos são regidas pelo mercado e não mais atendem às necessidades concretas dos consumidores. $O$ foco está nas necessidades e expectativas do produtor que precisa colocar suas mercadorias em circulação. A estreita relação entre consumo e obsolescência tinha na abundância de materiais advindos da exploração da natureza a certeza do fornecimento incessante de recursos naturais para a produção frenética de bens. Cardoso (2008, p. 165-166) afirma: "A meta do sistema era estimular o consumo de reposição, aproveitando uma superabundância de materiais e de capacidade produtiva para manter o crescimento contínuo do todo".

É nesse cenário que ganham relevância social as atividades executadas por um profissional específico: o designer. Bonsiepe (2011, p. 88) considera o design "como uma ferramenta cognitiva" que, por meio de interfaces, consegue "facilitar a assimilação de informação" (p. 89). O autor enfatiza ainda que os "designers podem cumprir uma função importante na apresentação eficiente dos conhecimentos produzidos por outros especialistas" (p. 89). Nesse contexto, os designers podem ser considerados autônomos nos processos de comunicação de ideias, assim como podem estar subordinados ao marketing e à publicidade com o propósito de vender mais. É perceptível que tanto o designer quanto o publicitário comunicam ideias, imagens, afetos e símbolos, as quais poderão, ou não, estimular o consumo.

A indústria não tardou a perceber, especialmente no decorrer do século 20, que a variação na taxa de lucro passa por transformações relevantes e demanda novas maneiras de se relacionar com o público consumidor. Diante da obsolescência programada, das ações do design e da disseminação publicitária, cabia voltar a atenção para a maneira de produzir e ofertar as mercadorias. Nesse contexto, o desenho dos produtos e a maneira de torná-los visíveis, atrativos e acessíveis à população passaram a ser o alvo da indústria e do mercado. 
A estética e a beleza do produto tornaram-se, assim, o objetivo dos profissionais que se dedicam tanto aos projetos de produto quanto à sua apresentação gráfica, o que, mais tarde, nos anos 50, cooperaria para disseminar a prática sistemática da obsolescência programada. A falta de mudanças reais e funcionais nos produtos, alterando apenas seu estilo, poderia contribuir para criar ilusões de novidades apresentadas ao consumidor, preservando ou aumentando os índices de vendas.

Eppinghaus (1999, p. 9), ao abordar a área do design responsável pelos projetos industriais e gráficos, observou que enquanto a perspectiva social do projetar na Europa estabelecia "uma objetividade técnico-material e uma funcionalidade formal", no lado norte-americano os designers eram doutrinados para criar produtos com apelo visual, que incitassem o consumo e aumentassem as vendas. Nesse sentido, cresceram as escolas de design que se propunham a desenvolver técnicas de aprimoramento de produtos. Uma das referências do design, que se perpetuou na segunda metade do século 20, foi a Escola Bauhaus, com sede na Alemanha, que foi inaugurada em 1919. Ela priorizava a criação de produtos baseados nas necessidades humanas. Os projetos consideravam a funcionalidade do objeto além de sua longevidade e também de sua estética, uma vez que a elaboração de projetos dessa escola visava a reconectar a arte e o artesanato, com o intuito de humanizar o design (GROPIUS, 1972; MALDONADO, 1981).

A profissão do designer foi estabelecida nos Estados Unidos "em 1930 como consequência direta da quebra da Bolsa em 1929. No contexto de uma crise econômica, os fabricantes norte-americanos rapidamente perceberam o papel do design de produto no sucesso comercial" (MOZOTA, 2011, p. 38). Devido ao cenário que a quebra da Bolsa acarretou, a indústria de bens requeria um aquecimento do mercado, no qual o designer interviu diretamente. Ele participou de tal aquecimento ao transformar bens produzidos em grandes quantidades em objetos desejáveis e únicos para quem os consumia. A maneira de projetar norte-americana passou a ser indispensável às indústrias do mundo (MOZOTA, 2011; WOLLNER, 2002; FORTY, 2000), associada à divulgação, por intermédio da publicidade e da criação de interfaces que também vendiam a ideia de obsolescência (EPPINGHAUS, 1999).

É nesse sentido que as atividades realizadas pelo designer podem ser consideradas um tipo de trabalho imaterial (HARDT; NEGRI, 2001). Ele pressupõe um esforço subjetivo, impalpável, tênue e singular, cujo desfecho será a concretização de uma peça virtual ou real, que apresente a funcionalidade, o simbolismo e a estética pretendidos por seus clientes. Pazmino (2015) aborda o trabalho imaterial do designer ao mencionar o pensar como parte do processo metodológico quando destaca:

O método tende também a ampliar tanto o problema de design como a busca de soluções adequadas, já que estimula e permite pensar além da primeira solução que vem na mente do designer. Outra vantagem do uso de métodos está relacionada à exteriorização do pensamento de design, ou seja, o método tenta extrair o pensamento e os processos mentais da mente e colocá-los em esquemas e gráficos (p. 9).

Ocorre que, em larga medida, a função criadora do designer nas indústrias foi absorvida pelo mercado a fim de aumentar os lucros das organizações, o que demandou de sua parte seguir métodos, como os mencionados anteriormente, constituídos por etapas, que contribuíssem para a lógica de acumulação do capitalismo. 0 design de- 
senvolvido no Brasil priorizou, majoritariamente, a questão econômica, reproduzindo objetos que tiveram êxito nos países da Europa, por exemplo. Bonsiepe (2011), a partir de seus estudos sobre as diferenças políticas e econômicas entre o centro e a periferia, deixa claro que o problema a ser enfrentado por esse profissional e também pela sociedade é muito maior do que os prejuízos econômicos. Ele estende-se para as práticas desenfreadas de consumo que ocorrem em diferentes escalas, as quais dependem da situação econômica dos países (desenvolvidos ou economicamente mais pobres).

Vale lembrar que o pós-fordismo, que ocorreu por volta da década de 70, forneceu subsídios para sofisticar o processo de produção que, até hoje, permanecem nas organizações. Essa nova maneira de organizar o trabalho, orientada para o crescimento e expansão, levou também a uma maior exploração dos recursos naturais. Conforme argumentado, o sistema rígido da produção em massa sofreu mudanças profundas, mas o consumo continuou sendo estimulado pelos novos planejadores que, segundo Kumar (1997, p. 66) pertencem a uma "nova classe de serviço baseada na mídia, nas universidades e nas indústrias da tecnologia da informação".

É inegável a função social do design na história da produção de mercadorias, uma vez que o consumo, como prática relacionada à satisfação e ao prazer, envolve aspectos subjetivos que vão muito além da exploração de matérias-primas e da produção de bens. Reconhecendo a relevância do design, o mercado percebeu que a partir de suas intervenções houve um aquecimento da economia. Esse ciclo tem por demanda um sistema de produção que concebe e produz mercadorias diversificadas para atrair a atenção dos consumidores. Para Papanek (2008, p. 38, tradução das autoras), "apesar de uma situação econômica que ameaça, os designers devem contribuir para as reais necessidades humanas e sociais. Isto exigirá grandes sacrifícios e um trabalho muito mais inovador". Isso nos leva a questionar para onde esse projeto exploratório poderá nos levar enquanto coletividade que depende da natureza para sobreviver. Daí a relevância de conhecer as maneiras como os designers trabalham no cotidiano, o que será apresentado na parte empírica deste estudo.

\section{PERCURSO METODOLÓGICO}

Antes, porém, cabe esclarecer o percurso metodológico desta pesquisa. Segundo Godoi, Bandeira-de-Mello e Silva (2006), ao realizar uma investigação, por meio da pesquisa qualitativa, fica implícito que o pesquisador se dedica à busca de singularidades e outras nuances que também são imprescindíveis para a produção do conhecimento científico. Os autores assinalam que "o que esperamos hoje é menos conversa sobre rigor e mais sobre originalidade, para que o conhecimento recupere o seu encantamento" (GODOI; BANDEIRA-DE-MELLO; SILVA, 2006, p. 5). A opção pela pesquisa qualitativa neste estudo permitiu acessar a realidade social dos designers que foi observada, discutida e analisada.

Para tanto, elegeu-se como estratégia o estudo de caso. Este pode ser compreendido como "um tipo de pesquisa cujo objeto é uma unidade que se analisa profundamente. Visa ao exame detalhado de um ambiente, de um simples sujeito ou de uma situação em particular" (GODOY, 1995a, p. 25). O estudo de caso, aqui proposto, foi delimitado em dois estúdios de design, contando com a participação de quatro profissionais. Primeiro, foram entrevistados dois profissionais que atuam em um estúdio es- 
pecializado na criação de marcas para organizações, além da criação de cartazes, capas de livros, rótulos e demais composições gráficas, doravante denominado Estúdio DG. 0 segundo estúdio, denominado Estúdio PP, participou da pesquisa com dois designers, que trabalham no desenvolvimento de projetos de produtos, desde a criação de joias a fachadas de lojas comerciais. Os profissionais participantes atuam em cidades localizadas no interior do Estado do Paraná e foram selecionados em razão da experiência acumulada na área. Para evitar a identificação, os designers tiveram seus nomes alterados e foram apresentados na seção seguinte como: João e Julia, pertencentes ao Estúdio DG, e Clara e Lucas, que atuam no Estúdio PP.

Os dados foram coletados por meio de três instrumentos: pesquisa documental, observações e entrevistas. Primeiro, foi realizada uma pesquisa documental nos sites dos estúdios a fim de conhecer como eles foram constituídos, quais suas produções e projetos, como fazem a gestão de suas atividades e quais os métodos e estratégias empregados. O segundo instrumento englobou observações realizadas nos dois estúdios, com a presença dos entrevistados. Godoy (1995b) ressalta a importância da observação na pesquisa qualitativa, pois "quando observamos, estamos procurando apreender aparências, eventos" (GODOY, 1995b, p. 27). As observações serviram para melhor compreender o fluxo das atividades e as características específicas de cada estúdio. Por fim, foram realizadas entrevistas semiestruturadas com a finalidade de obter "dados objetivos e subjetivos" (MINAYO, 2002, p. 57) que contribuem para o enriquecimento da pesquisa, uma vez que, segundo a mesma autora, sua "principal função é retratar as experiências vivenciadas, bem como as definições fornecidas por pessoas, grupos ou organizações" (p. 58). As entrevistas foram realizadas com base em um roteiro que abordava dois temas: 1. A relação do designer com a profissão e com o mercado, 2. O lugar da sustentabilidade no trabalho do designer. Os diálogos foram gravados e transcritos com a anuência dos entrevistados que assinaram o Termo de Consentimento Livre e Esclarecido.

A organização e análise dos dados contemplaram os dois eixos utilizados no roteiro das entrevistas e se balizaram na parte teórica. Com isso, objetivou-se uma aproximação entre a teoria estudada e a prática cotidiana dos designers como forma de melhor contextualizar o tema de pesquisa aos estudos acadêmicos. Assim, as análises tiveram como suporte o referencial teórico abordado no início deste artigo.

\section{RESULTADOS: O Designer e o Meio Ambiente}

Nesta seção são apresentados os dados coletados nos estúdios anteriormente descritos. Para isso, os resultados foram organizados em dois eixos de análise: a relação do designer com a profissão e com o mercado e o lugar da sustentabilidade no trabalho do designer, apresentados separadamente na sequência.

\section{A Relação do Designer com a Profissão e com o Mercado}

O processo de criação do designer está delimitado por um mercado que se movimenta continuamente e que solicita desse trabalhador resultados que impactem positivamente a economia das empresas e dos clientes. Por meio da interação e comunicação que seus produtos e serviços estabelecem com os consumidores, os profissionais criam ou revisam os projetos, priorizando ações subjetivas e objetivas para fortalecer o elo 
desses indivíduos e o mercado. Segundo Löbach (2000, p. 140), o mercado espera que o designer seja um "produtor de idéias, recolhendo informações e utilizando-as na solução de problemas que lhe são apresentados". É o que encontramos no depoimento do participante, João que diz: "A gente cria um projeto, a gente cria uma linguagem, um sistema de linguagem para que uma marca ou uma pessoa ou quem quer que seja possa se comunicar, possa se expressar" (JOÃO, sócio e proprietário do Estúdio DG, 2018). A identidade visual de um produto ou marca é estabelecida a partir do conhecimento das características objetivas e subjetivas da organização, obtidas a partir da aproximação entre o designer e seu cliente. Essa aproximação pode ser entendida como uma das ações inerentes ao trabalho imaterial (HARDT; NEGRI, 2001).

Julia descreve a importância da aproximação com o cliente em sua profissão. Tal procedimento faz parte do cotidiano dos designers ao levantarem os dados para a realização de um serviço ou produto. Ela esclarece:

A primeira coisa, sempre, é o relacionamento com o cliente. É entender tudo o que pode ser feito, entender [...] as necessidades, entender como é a pessoa mesmo. A gente gosta muito de conversar. Conhecer assim, todo o caminho (do cliente) que chegou até a gente, até precisar do trabalho. E aí, depois disso, a gente começa a criar mesmo. A partir para esse lado do que pode ser feito, do projeto mesmo (JULIA, sócia e proprietária do Estúdio DG, 2018).

Nota-se que a atividade relacional faz parte do cotidiano dos designers que buscam captar as necessidades, expectativas e intenções da organização e clientes para comunicar e informar essas demandas ao mercado por intermédio de ideias que se transformam em imagens, textos e objetos. Quando a identidade visual está coerente com as propostas da empresa ela se transforma em um veículo de informação relevante que será explorado publicamente. João descreve:

Esse é o nosso carro-chefe: criar o sistema de identidade visual. Esse trabalho é uma expressão. Então a gente tem um trabalho de sensibilidade, de compreender o que precisa ser comunicado, para saber expressar isto de forma coerente. Por mais que o nosso foco seja a identidade visual, focado então para marcas a gente entende que esse processo, essa transposição, a gente consegue também fazer em, praticamente qualquer meio, qualquer aplicação visual necessária (JOÃO, sócio e proprietário do Estúdio DG, 2018).

Lazzarato (2006) mostra a importância crescente atribuída pelas empresas ao design e à publicidade nos sistemas capitalistas de produção e de comunicação, descrevendo os seguintes dados:

As empresas investem até $40 \%$ de seu capital de giro em marketing, publicidade, modelagem, design (na indústria do audiovisual americano, 50\% do orçamento de um filme vai para a promoção e lançamento). Hoje em dia, os investimentos na máquina de expressão podem ultrapassar amplamente os investimentos nas rubricas "trabalho" ou "meios de produção" (p. 102).

Os índices de investimentos justificam os motivos pelos quais os processos investigativos do design junto aos seus clientes são tão minuciosos. O valor que pode ser agregado a uma marca, além de render dividendos às organizações, irá contribuir para favorecer a conexão entre ela e o consumidor. Lucas esclarece o cotidiano de seu traba- 
Iho: "Eu desenvolvo objetos, a partir do zero ou faço um redesign, uma melhoria nesses objetos, escolhendo o material, o processo de fabricação e acompanho isso até o final, até o produto estar na gôndola" (LUCAS, sócio e proprietário do Estúdio PP, 2018). Lucas também aborda a relação de confiança que, sob seu ponto de vista, deve acontecer entre ele e seu cliente. Isto irá permitir, por meio do conhecimento do designer sobre suas atividades, que o projeto contemple a criação e as demandas de seu cliente:

Primeiro tem que ter uma confiança do meu cliente para saber que eu vou conseguir atender e chegar no final. E, ali, a relação é: eu vou desenvolvendo um projeto e vou dando retorno pra ele. Eu sempre deixo o meu cliente participar do projeto. Eu não chego e, praticamente, só entrego, como a maioria das empresas chegam e falam: Não, você me pagou pelo projeto, eu vou te entregar este final de acordo com o que eu decidir. Eu pego ele ou a equipe dele e trago para eles entenderem o meu trabalho e eu entender o chão de fábrica deles para fazer a adequação (LUCAS, sócio e proprietário do Estúdio PP, 2018).

Nota-se que a relação entre a organização e o designer é a condição para a realização do trabalho. A narrativa de Lucas mostra bem isso:

Eu fui lá prestar um serviço de escaneamento, um serviço bem bobo e, paralelo, estavam os donos da empresa conversando sobre um projeto que eles não iam conseguir fazer. Que era um totem torcido, de $12 \mathrm{~m}$ de altura e que, em todos os lugares do mundo, eles iam ter esse design. Eles não conheciam o meu trabalho ainda. Daí eu, sem perguntar para os meus sócios, bati em cima da mesa e falei: "Desculpa eu entrar no meio do assunto, eu faço". Aí, tipo assim: "Mas como assim, você faz? Você nem sabe do projeto". Foi um dos projetos que a gente voou e pegamos vários outros projetos com essa empresa. Porque eu fiz esse totem aí, que eles nem imaginavam que eu era apto a fazer esse serviço. Eles me trataram como: "Ah! Um designer... Ele sabe fazer umas coisinhas bobinhas, ali". Mas o processo de fabricação é a gente que entende. Aí eu bati isso na mesa e falei: "Não, eu faço!" Aí, fechou! Foi bem legal! Estão instalando no Brasil todo (LUCAS, sócio e proprietário do Estúdio $\mathrm{PP}, 2018)$.

Clara afirma ainda: "A gente fala que a gente quer ser reconhecido. Se tiver dinheiro, é uma consequência do trabalho. A gente quer ser reconhecido e deixar nosso legado" (CLARA, sócia e proprietária do Estúdio PP, 2018). Lazzarato (2006) esclarece que o consumo ganhou relevância diferenciada na contemporaneidade, quando sua prática passou a proporcionar a sensação de pertencimento a um lugar, que pode ser estendido não apenas aos consumidores, mas também aos criadores de bens e de serviços. O autor descreve: "Consumir não se reduz mais a comprar e a 'destruir' um serviço ou produto, como ensina a política e sua crítica, mas significa, sobretudo, pertencer a um mundo" (LAZZARATO, 2006, p. 100).

Os designers entrevistados demonstraram a preocupação de pertencer a um mundo profissional, serem aceitos por seus pares e obter o reconhecimento dos clientes. Além disso, o designer estabelece ao seu redor uma rede entre profissionais de diversas áreas, como engenheiros, operadores de máquinas, desenhistas, profissionais do marketing e de mídias, dos quais depende para finalizar seus projetos. Quanto à organização interna dos estúdios, os designers mantêm uma relação direta no grupo profissional que possibilita atingir os resultados esperados. Julia menciona: "Eu e o João 
já tínhamos uma forma muito natural de trabalhar, de divisão de trabalho. Ele sempre cuidou bastante da parte de ilustração e eu cuidei mais da parte de interferência gráfica, de construção da marca mesmo" (JULIA, sócia e proprietária do Estúdio DG, 2019).

Nota-se, pelos depoimentos até agora apresentados, que a interdisciplinaridade está bastante presente na área (MOZOTA, 2011), sendo considerada um diferencial para expandir a qualidade do trabalho prestado. Outro elemento presente é o uso de tecnologias. Para esse tipo de trabalho os profissionais contam com softwares que desenham e modelam o produto, fornecendo especificações técnicas do objeto (medidas, formatos, materiais, massa, etc.) e que se interconectam com impressoras de três dimensões (3D), que darão "forma" aos projetos. Essa atividade pode ser realizada por apenas um designer, cujas formas resultantes serão precisas e idênticas às criadas por ele. No caso da produção de joias, a designer consegue solucionar muitas etapas de seu processo produtivo em seu estúdio. A tecnologia é um fator importante para estes profissionais, que têm nessas alternativas ferramentas precisas para concretizarem suas criações (CASTELLS, 1999; GORZ, 2005). Lucas, ao ser questionado sobre as possibilidades proporcionadas pelo novo equipamento, avalia o impacto das vendas forçadas para pagar custos por falta de tecnologia, e menciona:

Incentivar ao consumo por quê? Porque o investimento tem que tirar o prejuízo, entendeu? A impressora 3D tá acabando com isso. Você projeta, imprime um, se vende um, beleza, se vender dois, ok! Você vende só o tanto que você produz. Não precisa fazer aquela linha de produção. Você nem sabe se vai vender! Vira aqueles barracões de acúmulo de coisas. Produto também. Quando você faz um investimento em um molde, produz milhares e fica acumulado. Porque o mercado não aceitou (LUCAS, sócio e proprietário do Estúdio PP, 2018).

Este eixo de análise permitiu entender que o trabalho dos designers pode ser identificado como imaterial, pois exige conhecimentos e habilidades que vão além da materialização de peças gráficas ou de objetos. Está implícita em suas atividades a relevância das relações sociais, afetivas e de confiança para entender os desejos e as intenções de clientes e usuários. Lazzarato e Negri abordam essa apropriação da criação dos trabalhadores ao afirmarem:

Nessa transformação não é nem o trabalho imediato, executado pelo próprio homem nem é o tempo que ele trabalha, mas a apropriação de sua produtividade geral, a sua compreensão da natureza e do domínio sobre esta através de sua existência enquanto corpo social - em uma palavra, é o desenvolvimento do indivíduo social que se apresenta como o grande pilar da sustentação da produção e da riqueza (LAZZARATO; NEGRI, 2001, p. 28).

São notáveis, nas entrevistas, as exigências relacionais e afetivas colocadas pelo mercado, que se volta para resultados que dependem da sensibilidade, da socialização e de experiências pessoais acumulados na história relacional dos profissionais.

\section{O Lugar da Sustentabilidade no Trabalho do Designer}

Cabe agora compreender em quais momentos a sustentabilidade se faz presente nas atividades dos designers e que tipo de impasses ela coloca em curso nesse campo profissional. Como descrito no referencial teórico, o consumismo vem sendo construído historicamente como um componente de subjetivação destacado entre as deman- 
das dos sistemas capitalistas, especialmente após a Segunda Guerra Mundial (ROLNIK, 2003). As estratégias produtivas do designer pautaram-se na estimulação de necessidades e expectativas que constroem a prática social de consumo. Para isso, os profissionais se utilizam de cores, formas, imagens e outros apelos estéticos e simbólicos, com a finalidade de produzirem objetos que sejam interessantes aos olhos dos consumidores e que possam ser vendidos em larga escala. Assim, o consumo flui em alta velocidade para alimentar a máquina produtiva capitalista. João aborda essa produção de mercadorias que não cessa, questionando:

Será que a gente precisa disso tudo? Como espécie? Não é só (uma questão) pessoal. Eu acho que a gente começa a consumir induzido por sei lá quem. Mas é uma entidade que, na verdade, é o status quo, né? Não é uma pessoa. É a forma de como as coisas estão estabelecidas (JOÃO, sócio e proprietário do Estúdio DG, 2018).

Lucas também menciona as necessidades "inventadas" para que o indivíduo consuma, reportando-se às estratégias de marketing: "Esse exemplo é um dos maiores casos que tem. Do marketing saber manipular a cabeça do usuário, que ele precisa daquilo lá. Na verdade ele não precisa" (LUCAS, sócio e proprietário do Estúdio PP, 2018).

Pelos depoimentos, percebe-se que introduzir o indivíduo no circuito da produção-consumo faz parte da organização geral capitalista. Julia também critica as atividades do marketing que incentivam o consumo cego e propõe que se utilize essa ferramenta para que o consumidor/usuário se identifique com tal produto ou serviço. Com isso, para ela, haveria uma fidelização à marca, mas que não o conduziria, sempre, ao consumismo:

Eu acho bem ruim. O que a gente sempre tenta, é não a venda, o anúncio destas questões. É mais a fidelização, a identificação do consumidor com aquilo que tá sendo colocado. Às vezes, é mais a identificação com o produto do que a compra do produto. Eu acho que essa é uma diferença. Vai bombardear você de informações de venda e não sobre como vocês dois podem se relacionar. Mas esse próprio ato eu já acho ruim, sabe? De você ficar propagando isso, de você criar pensando nisso (JULIA, sócia e proprietária do Estúdio DG).

A disseminação das práticas de consumo não tem como primazia a preocupação com o meio ambiente, visto que o processo produtivo demandou e ainda demanda grandes quantidades de recursos naturais e humanos para sustentá-lo. Papanek (2008) identificou no design a promoção dessa lógica, mas, sobretudo, encontrou possibilidades, a partir desse profissional, de modificar o estabelecido. João, por exemplo, ao desenvolver um projeto gráfico para uma cliente, proprietária de um restaurante que não utiliza nenhum tipo de ingrediente de origem animal no preparo das refeições, viu-se diante de um desafio ao ser-lhe solicitada uma embalagem para alimentos que não poderia ser de plástico. A exigência colocada pela cliente era de evitar materiais que poluíssem o meio ambiente. João narra sua experiência:

A experiência mais próxima, mas que eu ainda acho muito superficial, a gente fez, recentemente: Foi a identidade visual de um café. É vegano, tem toda essa preocupação. E, para ser honesto mesmo, foi a primeira vez que a gente se preocupou realmente com as soluções. A gente fez de tudo para não esbarrar em coisa de plástico. Principalmente, falando de embalagem, de comunicação, porque por mais que a gente busque essas soluções, a gente vai, ainda, no que é funcional, 
infelizmente. Não vamos exagerar, não vamos destruir, não vamos nada! Só que, ao mesmo tempo, vamos buscar aqui o que fica mais barato para o cliente. Agora, quando foi fazer esse café, ela precisava de embalagem para levar. Não pode ser de isopor, não pode ser de plástico. E daí a gente foi mais longe, buscando outra solução (JOÃO, sócio e proprietário do Estúdio DG, 2018).

A exigência de produtos sustentáveis, advindas de clientes, não é algo muito comum em nossos dias. Assim como os proprietários de fábricas, é mais comum que os clientes coloquem os ganhos econômicos antes dos sustentáveis e, dificilmente, sua opção é pela proteção da natureza e dos indivíduos. Os designers, com base em sua formação, poderão atuar como mediadores entre os consumidores e a preservação da natureza, tomando em consideração as dimensões sustentáveis apontadas por Sachs (2007) anteriormente. Segundo Manzini e Vezzoli (2005), o designer pode utilizar de habilidades e conhecimentos para propor produtos e serviços sustentáveis, instigando os consumidores a visualizarem outras práticas possíveis. Por sua vez, Maldonado (2012) mostra que as práticas dos designers os inserem em contextos culturais, filosóficos e políticos. Com isso, entende que suas criações devem ir muito além das disciplinas estritamente técnicas ou estéticas, buscando também soluções sustentáveis para viabilizar seus projetos (MALDONADO, 2012). Sensível a esse quadro, Julia usa a metáfora da ponte para explicar como o designer poderá auxiliar no processo mais sustentável:

Acho que a gente é como meio, como uma ponte entre o projeto e o físico. $O$ resultado: A gente pode mudar muita coisa nessa conexão. Além do próprio trabalho de modificar, de tentar deixar um pouco menos agressivo, mais sustentável (JULIA, sócia e proprietária do Estúdio DG, 2018).

Essa ponte está amparada na relação designer-cliente presente nos trabalhos desenvolvidos tanto pelos designers gráficos quanto pelos de produto. Ela pode servir para disseminar, entre os clientes, a importância de preservar o meio ambiente, fomentando o crescimento das vendas, da produção, da utilização de recursos ambientais e humanos que não tenham como consequência a degradação do planeta. Papanek (2008) critica o trabalho dos designers que restringem sua criação para o topo da pirâmide social de consumo, deixando de lado as reais necessidades sociais, cenário que ocorre tanto nos países ricos quanto naqueles que apresentam uma economia mais frágil.

Bonsiepe (2006), ao abordar a inserção dessa profissão em sistemas capitalistas, menciona que não apenas os designers, mas profissionais de outras áreas também apresentam dificuldades em solucionar problemas de "grupos excluídos, discriminados e economicamente desfavorecidos (como eles são chamados, no jargão economista), o que equivale à maioria da população deste planeta" (p. 30, tradução nossa). O autor enfatiza:

Quero deixar claro que não proponho uma atitude universalista de acordo com o padrão de design do mundo. Além disso, não acredito que essa afirmação deva ser interpretada como a expressão do idealismo ingênuo, supostamente fora de contato com a realidade. Pelo contrário, cada profissão deve enfrentar essa questão desconfortável, não apenas a profissão de designers. Seria um erro aceitar essa afirmação como a expressão de um pedido normativo de como um designer - exposto à pressão do mercado e às antinomias entre a realidade e o que poderia ser a realidade - deveria agir hoje. A intenção é mais modesta, isto é, fomentar 
uma consciência crítica diante do enorme desequilíbrio entre o centro de poder e o povo submetido a esses poderes, porque o desequilíbrio é profundamente subdemocrático na medida em que nega a participação. Ele trata os seres humanos como meras instâncias no processo de objetivação (Verdinglichung) e mercantilização (BONSIEPE, 2006, p. 30, tradução das autoras).

Os designers de produto entrevistados sentem dificuldades de agir de maneira sustentável diante do mercado, pois ele exige resultados que contemplem o acelerado processo de produzir e consumir. Lucas menciona: "Um ciclo desenfreado de consumo, que é difícil controlar" (LUCAS, sócio e proprietário do Estúdio PP, 2018). Ele assinala que são as "empresas que incentivam isso. Tem que alimentar a venda deles, e o consumidor já se viciou nisso, em ter que comprar para trocar num futuro". Clara aborda algumas possibilidades para que as empresas que produzem bens de consumo repensem seus valores ao oferecerem produtos que tenham uma maior durabilidade. Ela ressalta a possibilidade de:

Fazer algumas alterações dos produtos. Demora um pouco mais de tempo para desenvolver um produto. Então, que seja realmente bom, para você não ter que fazer um novo, todo ano. Gasta uma energia fazendo um negócio que vai durar mais tempo (CLARA, sócia e proprietária do Estúdio PP, 2018).

Kazazian (2005) corrobora com o pensamento da designer quando menciona:

Produzir sem destruir e conceber um objeto do cotidiano, do mais elementar ao mais sutil, tornando seu uso durável e seu fim assimilável por outros processos de vida, deve ser uma reflexão global que consideraria a complexidade dessa relação (p. 28).

Outra ideia apresentada pelos designers nas entrevistas é a possibilidade de constituir pequenas empresas capazes de utilizar menores quantidades de recursos naturais e também produzir menores níveis de degradação ambiental. João, ao falar das dimensões ambientais e sociais, contribui para que se entenda como as condições e arranjos dos locais de trabalho conduzem a inúmeros impactos e destruição:

A imagem da fábrica, cuspindo um monte de fumaça, beleza! Aquilo é a destruição ambiental. Mas se você pegar a imagem de um escritório em Nova lorque (cidade norte-americana), que é aquele monte de baia, e todo mundo trabalhar sem se conhecer e aquela maluquice. Isso também é uma destruição social. Isso é um impacto gigantesco. Hoje em dia a gente precisa falar disso (JOÃO, sócio e proprietário do Estúdio DG, 2018).

Clara afirma que os proprietários de pequenas organizações se veem livres para criar ou conceber seus negócios, ao desvincularem-se de seus antigos cargos dentro de empresas:

As pessoas que trabalham lá dentro trabalham tristes, porque elas trabalham sobre regras rígidas para a empresa funcionar. Então, assim, ela não tem o direito de ser criativa, ela não tem direito de criar as coisas dela. Daí essa procura por ter a sua própria empresa, ter o seu próprio negócio, o seu próprio ritmo de trabalho. Esse tipo de coisa deixa as pessoas muito mais felizes. E essa onda de incentivo de comprar de quem faz, esse tipo de coisa, a gente entra nessa também (CLARA, sócia e proprietária do Estúdio PP, 2018). 
A designer também aborda mudanças que ocorreram em seu trabalho de criação e que foram mais sustentáveis. Ela relata o caso de um cliente que desejava trabalhar com o metal latão, fato que traria mais prejuízos desnecessários à natureza. Ao esclarecer ao cliente o quanto seria interessante optar pela prata no lugar do latão, mostrou que a troca desse material minimizaria aplicações de substâncias tóxicas sobre o latão, a fim de deixá-lo com um aspecto brilhante, prateado. O valor da prata é mais alto que o do latão, entretanto os designers optaram pela prata porque ela evita os "banhos" tóxicos necessários para dar brilho e textura ao outro metal. Lucas (sócio e proprietário do Estúdio PP, 2018) diz: "Banho também tem um impacto ambiental gigantesco", pois, muitas vezes, os fornecedores que aplicam esse banho não apresentam uma estrutura para o descarte correto dessas substâncias. Sobre esse mesmo tema, Clara relata sua experiência:

Eles custam para a gente a mesma coisa (os metais mencionados). Basicamente, tem uma diferença pouca de custos. Realmente, o latão é mais barato. Mas o acabamento do latão é pior, é mais difícil de fazer. Eu preciso dar um banho no latão. E daí, eu tenho uma logística ruim também de banho: tenho que mandar para alguém dar esse banho, para daí voltar pra cá. A gente sempre deu prioridade para trabalhar com ouro e prata porque a gente já tem esse respaldo de resolver as coisas por aqui mesmo, de uma forma mais simples (CLARA, sócia e proprietária do Estúdio PP, 2018).

De acordo com Kazazian (2005), pequenas mudanças nos processos produtivos podem viabilizar os "acordos férteis" que levam a uma "economia leve" (p. 28). Julia relatou sua experiência e a tentativa de reduzir impressos, pensando na economia que proporcionaria aos seus clientes e na redução dos impactos ambientais:

As escolhas geralmente dependem da gente, nessa questão de aplicação, do que vai usar. E aí a gente tem que pensar como isso vai afetar no projeto. Eu acho que a gente tem a escolha: reduzir ou utilizar o material mais adequado, às vezes fazer menos material, convencer o cliente também de que aquilo, não precisa imprimir 5.000 , pode imprimir tipo 1.000 que vai dar a mesma coisa. No próprio caso do bar (cliente do estúdio): queriam fazer um monte de coisa impressa. Por que é que não coloca no instagram? Tira um print. Não precisa imprimir um monte. Daí eles imprimiram e não deu certo, no final das contas. Era um papelzinho assim, que era um vale chopp! E a gente falou que poderia ser um print no celular, que a pessoa tirava e levava. Não precisava imprimir (JULIA, sócia e proprietária do Estúdio DG, 2018).

Já nos processos produtivos industriais existem diferenças. Julia relata ser quase impossível que o trabalho do designer, em organizações, consiga essa leveza, pois se esperam resultados compatíveis com os meios de produção estabelecidos em escala maior. Ela coloca dúvidas sobre a possibilidade de transformação desses processos nas indústrias, mencionando:

Eu acho que a questão, na indústria, é muito mais complicada, porque você já tem toda uma definição do que tem que ser feito. É limitada mesmo, dentro de cada empresa. Por exemplo, vou projetar essa garrafa (aponta para o objeto sobre a mesa). Já vai ter a máquina lá que só faz aquilo, então eu tenho que bolar alguma coisa para aquilo! Não posso sair! (JULIA, sócia e proprietária do Estúdio DG, 2018). 
Cabe, aqui, relembrar a teoria que Castro (2004) defende sobre os tecnocratas e planejadores: Eles não querem que haja questionamentos sobre a possível transformação e desvinculação de uma lógica capitalista naturalizada. Os profissionais do sistema administrativo e gestor têm por objetivo apenas os resultados que envolvem lucro. Eles capacitam os trabalhadores para este único fim: "Para pedir-lhes a melhor maneira de alcançar esses objetivos" (p. 201).

As possibilidades de adotar práticas sustentáveis são amparadas por questionamentos e conhecimentos que promovem pequenas transformações no cotidiano. Tanto os designers de produto quanto os gráficos propõem, mesmo que estimulados por uma economia de custos, resultados que favoreçam o meio ambiente. Lucas menciona a importância do conhecimento para as mudanças: "Quanto mais a gente pesquisa, a gente estuda, vai aparecendo mais materiais, mais processos de fabricação e a gente consegue lincar" (LUCAS, sócio e proprietário do Estúdio PP). A designer Clara, no entanto, manifesta-se com apreensão sobre o futuro, abordando a importância da sustentabilidade no mundo:

Além de relevante é totalmente necessária. É impossível não se preocupar com isso. Porque, do jeito que tá, não tem futuro. Não tem o que fazer. Não tem para onde ir. A gente vai morar em um monte de lixo. As pessoas que consomem tanto acham que não é a realidade delas. Que nunca vai acontecer. Que quem vai sofrer são os mais pobres. Só que assim, vai chegar para todo mundo! (CLARA, sócia e proprietária do Estúdio PP, 2018).

Clara entende que quanto mais nos afastamos do conhecimento sobre a degradação ambiental e suas consequências, mantendo os hábitos de um consumidor que compra e descarta sem pensar, mais a degradação avança. E faz um alerta: "E aí eles acham, simplesmente, que doando as coisas que eles não usam para os mais carentes, o impacto sumiu. Você tá dando uma segunda vida para o produto? Tá! Tá entulhando a casa do coitado do pobre? Também, tá !" (CLARA, sócia e proprietária do Estúdio PP).

Abordando a reciclagem de materiais, a designer tem projetos que utilizam materiais reciclados para compor suas joias, tais como pedacinhos de pranchas de madeira, que compõem os skates. Clara relata:

E tem esse processo que eu estava contando, que é um processo de segunda vida útil de alguns produtos. Dentro da joia tem como você usar muito material alternativo, para fazer muita coisa, e tipo, usar o material alternativo significa que você vai dar uma outra vida para aquela peça. A joia termina as coisas. Então é, tipo, a marca de fazer skate. O skate quebra e você não consegue reaproveitar isso. Não é orgânico, é empedrada. Então, você pega esse produto, que é bonito, que é colorido e daí você faz a marchetaria, faz todos os desenhos e você vai gerar um novo produto, que é uma joia, que vai durar para sempre (CLARA, sócia e proprietária do Estúdio PP, 2018).

Ao mesmo tempo, Clara chama a atenção para um preconceito da população para com os objetos advindos de materiais reciclados: 
Você tem como criar esse segundo ciclo de vida sem parecer aquela coisa lixão, reaproveitada, que é a cara do reciclado. Quando a gente fala que é reciclado, a turma já fala: "Ah! Vai ter aquela cara que é um negócio pintado, garrafa PET, pneu de caminhão, pneu de carro". Você consegue criar muito produto com segunda vida (CLARA, sócia e proprietária do Estúdio PP, 2018).

Os designers veem nessas pequenas empresas caminhos para a valorização de sua profissão e para o que compreendem como sustentabilidade: além de poder reduzir o consumo, ao produzir sob demanda e por meio da tecnologia, existe a contribuição para incentivar a autonomia do trabalhador, que irá planejar seus ganhos e sua jornada de trabalho.

Lucas já tinha abordado sobre a impressão 3D, nas análises da categoria anterior, ao mencionar que essa tecnologia permite que um objeto seja fabricado e vendido, sem haver a necessidade da produção de bens em massa, evitando o excedente e o descartado. Clara descreve como a tecnologia poderá impactar a produção: "Você fabrica o tanto que você precisa vender. Esse é um exemplo maior do que tá dando impacto na sociedade mundial, com a tecnologia. Com essa nova tecnologia" (CLARA, sócia e proprietária do Estúdio PP, 2018).

Kazazian (2005) aborda a importância da inovação nas organizações como possibilidades para a desmaterialização, como fator inerente às propostas sustentáveis dos processos produtivos de bens:

Outras motivações podem existir, principalmente a melhora da qualidade dos produtos, a redução dos custos e o estímulo interno para a inovação. A exigência ambiental estimula a criatividade e pode estar na origem de maiores evoluções: novas funcionalidades, novos materiais, novas tecnologias, novos usos... (p. 36).

A desmaterialização pode ser praticada "reduzindo em absoluto a busca por produtos e serviços, e/ou aumentando a inteligência do sistema produtivo existente, reduzindo assim o fluxo de matéria e energia necessárias para seu funcionamento" (MANZINI; VEZZOLI, 2005, p. 36). Lucas demonstra satisfação ao mencionar as possibilidades de atuar contra a lógica produtiva contemporânea:

É a desmaterialização. E o design, os escritórios de design estão acabando com a necessidade das grandes multinacionais, de fabricações de muitas peças. Você chega aqui no nosso escritório, pede uma peça exclusiva, sua, com a sua cara e que vai, praticamente, com o mesmo custo deles. A gente consegue chegar. Daqui para frente vai ser mais personalizado, entendeu? E você não precisa produzir para miIhares de pessoas. Você produz para uma, duas (LUCAS, sócio e proprietário do Estúdio PP, 2018).

Nota-se que, a partir dos relatos, o modelo produtivo baseado em grandes escalas de criação de produtos poderá retornar, futuramente, ao modelo artesanal, mas agora alicerçado na alta tecnologia, transformando-se em uma espécie de artesanato high-tech. Isto também pode ser notado em sistemas produtivos gráficos, cujas produções de impressos já estão tendo quantidades reduzidas, conforme as demandas apresentadas por consumidores distintos. Essas produções são auxiliadas pela tecnologia, que fornece qualidade na impressão, processos mais limpos (menores usos de substâncias tóxicas) e custos baixos. 
Ao final das entrevistas, os designers foram questionados sobre a existência de um dilema entre o seu trabalho: atuar na interface entre o mercado e a sustentabilidade. Lucas manifestou-se enfaticamente:

Existe um dilema muito grande entre o designer e a sustentabilidade, porque é difícil você colocar as suas ideias e sempre ser sustentável. Sempre encontra barreira de processo de fabricação, de materiais e custo também. Então, sempre tem essa barreira no design. E cultura de aceitabilidade daquilo ali, do reciclado. É difícil aplicar e dar uma estética bonita, às vezes. É muito limitado. Acaba limitando muito o projeto (LUCAS, sócio e proprietário do Estúdio PP, 2018).

As atividades dos designers, inicialmente, foram direcionadas para o aumento dos lucros das organizações ao priorizarem as vendas e o consumidor (LÖBACH, 2000). Modificar essa lógica requer tempo, assim como disposição dos profissionais para trilhar um caminho difícil de conectar as habilidades e competências do designer à sustentabilidade. Assim como outras atividades profissionais, entretanto, nota-se que o entendimento da urgência em preservar o meio ambiente está cada vez mais evidente.

\section{CONSIDERAÇÕES FINAIS}

Ao final deste estudo cabe destacar que o designer, assim como outros profissionais da área de criação, está inserido em um sistema capitalista que estimula e absorve seu trabalho, visando lucros. A dinâmica de lançamento, superação e apresentação continuada de novidades é o que confere ao capitalismo a força de perpetuação. $A$ inquietação que advém dessa prática de acúmulo incessante é sua inevitável instabilidade e alargamento de riscos quando se considera os limites da exploração predatória da natureza e dos humanos. Como apresentado no decorrer da pesquisa, o designer é convocado a manter essa lógica produtiva, estabelecendo uma relação de aproximação direta com o sistema.

A articulação entre a teoria e a prática buscada nesta pesquisa possibilitou o delineamento de quatro conclusões:

1. O designer está diante de possibilidades concretas de atuar de maneira sustentável, distanciando-se de uma produção capitalista realizada de maneira predatória. Quando bem informado sobre materiais e produtos, mas também com uma formação acadêmica que englobe questões políticas e éticas sobre os limites da natureza, seu trabalho pode apresentar um leque amplo de intervenções mais sustentáveis;

2. Caso isso não seja feito, os designers tendem a considerar, em seus projetos, apenas requisitos funcionais, estéticos, simbólicos, técnicos, ergonômicos e econômicos, em detrimento dos requisitos ambientais, sociais e culturais deixados, comumente, em um segundo plano. Essa desconexão com a natureza e com o planeta pode ser explicada, em alguma medida, pela dificuldade presente nos cursos de Graduação que não abordam ou abordam superficialmente o tema;

3. Os teóricos do design, mencionados no presente trabalho, tomam em consideração a importância da interação do design com as questões ambientais que afetam o planeta, o que proporciona um entendimento sobre as possibi- 
lidades que ele pode oferecer para minimizar os problemas das sociedades. Assim, sua ação profissional poderá melhorar as condições de vida humana e ambiental;

4. É nesse sentido que consideramos o quanto essa profissão, que historicamente manteve-se amplamente aliada da produção industrial predatória, carece de uma formação e análise crítica sobre os impasses presentes na relação entre o homem e a natureza. Ancorar a preocupação com o meio ambiente em um momento posterior ao processo educacional irá depender do envolvimento do designer com a sustentabilidade. Mesmo porque, a depender do mercado, esse momento nunca virá.

Nesta pesquisa foi possível abordar os impasses incontornáveis com os quais se deparam os profissionais do design neste momento histórico: mesmo imerso nesse sistema de produção, como é possível assumir uma postura mais sustentável, que tome em consideração os limites da natureza, sua temporalidade e suas necessidades de reposição? Somente enfrentando esse problema de frente será possível aumentar o alcance de suas ações, cooperando para criar soluções sustentáveis na elaboração de produtos que de fato tragam melhorias sociais e ambientais. Nesse sentido, pode-se concluir que as atividades do designer ainda carecem de estudos críticos que coloquem essa área mais próxima dos problemas ambientais e mais comprometida com a sustentabilidade. Certamente, tais profissionais têm muito a colaborar na criação de produtos, usos e estilos de vida que sejam mais sustentáveis.

\section{REFERÊNCIAS}

BAUDRILLARD, J. A sociedade de consumo. Coimbra, Portugal: Edições 70, 2008a.

BAUDRILLARD, J. O sistema dos objetos. 5. ed. São Paulo: Perspectiva, 2008b.

BONSIEPE, G. Design and Democracy. In: Design Issues, v. 2, n. 2, 2006. Disponível em: https://www.mitpressjournals.org/doi/pdf/10.1162/desi.2006.22.2.27. Acesso em: 5 jan. 2019.

BONSIEPE, G. Design, cultura e sociedade. São Paulo: Blücher, 2011.

CARDOSO, R. Uma introdução à história do design. São Paulo: Edgard Blücher, 2008.

CASTELLS, M. A sociedade em rede. São Paulo: Paz e Terra, 1999.

CASTRO, C. J. Sustainable Development: Mainstream and Critical Perspectives. Organization \& Environment, v. 17, n. 2, p. 195-225, jun. 2004.

EPPINGHAUS, R. H. G. Design moderno: limitações terminológicas. Estudos em Design, Rio de Janeiro, v. 7, n. 2, p. 55-75, ago. 1999.

FERRARA, L. D. Olhar periférico: informação, linguagem, percepção ambiental. São Paulo: Edusp, 1999.

FORTY, A. Objetos de desejo: design e sociedade desde 1750. São Paulo: Cosac Naify, 2007.

GODOI, C. K.; BANDEIRA-DE-MELLO, R.; SILVA, A. B. Pesquisa qualitativa e o debate sobre a propriedade do pesquisador. In: GODOI, C. K.; BANDEIRA-DE-MELLO, R.; SILVA, A. B. (org.). Pesquisa qualitativa em estudos organizacionais: paradigmas, estratégias e métodos. São Paulo: Saraiva, 2006. p. 1-13.

GODOY, A. Introdução à pesquisa qualitativa e suas possibilidades. Revista de Administração de Empresas, São Paulo, v. 35, n. 2, p. 57-63, mar./abr. 1995a.

GODOY, A. Pesquisa Qualitativa: tipos fundamentais. Revista de Administração de Empresas, São Paulo, v. 35, n. 3, p. 20-29, maio/jun. 1995 b.

GORZ, A. O imaterial. São Paulo: Annablume, 2005.

GROPIUS, W. Bauhaus: Novarquitetura. São Paulo: Editora Perspectiva, 1972.

HARDT, M.; NEGRI, A. Império. Rio de Janeiro: Record, 2001.

HOBSBAWM, E. Era dos extremos: breve história do século XX. São Paulo: Companhia das Letras, 1995.

HOLANDA, S. B. Cobra de vidro. 2. ed. São Paulo: Perspectiva, 1978.

KAZAZIAN, T. Haverá a idade das coisas leves: design e desenvolvimento sustentável. São Paulo: Editora Senac, 2005. 
KUMAR, K. Da sociedade pós-industrial à pós-moderna: novas teorias sobre o mundo contemporâneo. Rio de Janeiro: Jorge Zahar Ed., 1997.

LAZZARATO, M. As revoluções do capitalismo. Rio de Janeiro: Civilização Brasileira, 2006.

LAZZARATO, M.; NEGRI, A. Trabalho imaterial: formas de vida e produção de subjetividade. Rio de Janeiro: DP\&A, 2001.

LÖBACH, B. Design industrial: bases para a configuração dos produtos industriais. São Paulo: Editora Edgard Blücher, 2000.

MALDONADO, T. El disegño industrial reconsiderado. Barcelona: Gustavo Gili, 1981.

MALDONADO, T. Cultura, sociedade e técnica. São Paulo: Blücher, 2012.

MANZINI, E.; VEZZOLI. C. O desenvolvimento de produtos sustentáveis: os requisitos ambientais dos produtos industriais. São Paulo: Edusp, 2005.

MINAYO, M. C. S. Pesquisa social: teoria, método e criatividade. Petrópolis: Editora Vozes, 2002.

MOZOTA, B. B. Gestão do design: usando o design para construir valor de marca e inovação corporativa. Porto Alegre: Bookman, 2011.

O'CONNOR, J. ¿Es posible el capitalismo sostenible? Pap. Poblac, Toluca, v. 6, n. 24, p. 9-35, p. 27-52, jun. 2002.

PAPANEK, V. Design for the real world: Human ecology and social change. London: Thames \& Hudson, 2008.

PAZMINO, A. V. Como se cria: 40 métodos para design de produtos. São Paulo: Editora Blücher, 2015.

ROLNIK, S. O ocaso da vítima: para além da cafetinagem da criação e de sua separação da resistência. São Paulo: ARS, 2003. p. 79-87.

SACHS, I. Rumo à ecossocioeconomia: teoria e prática do desenvolvimento. Rio de Janeiro: Garamond, 2007.

SODRÉ, S. W. Formação histórica do Brasil. Rio de Janeiro: Editora Brasiliense. 1963.

TOTA, A. P. O imperialismo sedutor: a americanização do Brasil na época da Segunda Guerra. São Paulo: Companhia das Letras, 2009.

WOLLNER, A. Textos recentes e escritos históricos. São Paulo: Editora Rosari, 2002. 